\title{
Learning Approaches Related to Perception of Assessment in Students at Higher
}

\author{
Education Level \\ * Asima Jaffar, PhD Scholar (Corresponding Author) \\ ** Dr. Saeed Anwar, Ex Dean Social Sciences \\ *** Dr. Syed Manzoor Hussain Shah, Dean Social Sciences
}

\begin{abstract}
The students' perception of classroom assessment impacts their approaches towards learning. Therefore, it is a demand for Higher education institutions to reassess their assessment procedures to face the challenges posed by the changing world, and to increase the competencies of the students for their workplaces in the future. The present study aims to correlate students' learning approaches and their perception of assessment task at higher education level, using canonical analysis. The sample consisted of 468 master level students, selected randomly, of 10 general universities of Khyber Pakhtunkhwa, Pakistan. Results showed that students relied on surface strategies, leading to cramming, which was allied with a high degree of authenticity of assessment. Alternate assessment strategies like peer and self-assessment can encourage conceptual learning in students and turn will help them become competent at the workplace.
\end{abstract}

Keywords: Formative Assessment, Learning Approaches, Students' Perception of Assessment Task, Canonical Analysis, Authenticity of Assessment

\section{Introduction}

In the contemporary globalized transformational change in higher education, higher education institutions are direly needed to explore their purpose of assessment which is an essential component of the teaching and learning process. It persuades to organize learners to compete at the workplace with their competencies of the $21^{\text {st }}$ century. It is the main tool in judging the increase in student learning and its applicability (Klimoski, 2006). However, this process requires vigilant and systematic assembling of students' enriched learning shreds of evidence (Palomba \& Banta, 1999).

The present study aims to relate five dimensions of the assessment task used by Dorman \& Knightley (2006) along with the feedback provided in the classroom, to the learning approaches of students, using canonical correlation models for the 468 students of master level university students of Khyber Pakhtunkhwa, Pakistan. In this regard, the canonical correlation analysis was used because it helps in understanding the multivariate relationship of students' assessment perception and their strategies of learning. The university students were chosen because they will be a part of the workplace after 16-year education. Thus, they can better explain their past experiences. Subjects of science and mathematics were chosen as these subjects can be taught by a variety of methods. These subjects are studied by students of diverse abilities and high-performance. The Khyber Pakhtunkhwa (KP) area of Pakistan was chosen because it lacks the education facilities as compared to the developed parts of the country.

\section{Literature Review}

Several factors influence students' learning including individual differences, background knowledge, beliefs, and expectations. It is the ongoing assessment during classroom teaching which makes it possible for teachers to judge learned behavior according to designed instructions and improving it using feedback for enriched learning (Bransford, Brown \& Cocking, Council, 2000). Therefore, students' perception of assessment is essential for finding how they learn and to what extent do they use their learning to obtain good grades. Hence, ongoing assessment, also called formative assessment (Black \& Wiliam, 1998) plays an important role in developing students' learning rather than just

\footnotetext{
* Department of Education, Hazara University, Mansehra, Pakistan Email: asimajaffar@ yahoo.com

** Hazara University, Mansehra, Pakistan Email: saeedan44@yahoo.com

*** Hazara University, Mansehra, Pakistan Email: drmhshaah@ gmail.com
} 
memorization of facts for the attainment of best grades. Ongoing assessment in the classroom, productively, can be used to increase students' learning. According to Stiggins and Chappuis (2005) clear purpose, descriptive feedback, and involving students in the assessment process are some conditions for fruitful formative assessment. Research has shown that various dimensions of the assessment task in the classroom might account for the difference in terms of students' learning. In a research by Dorman and Knightley (2006), based on a sample of 658 science students of high school, five such dimensions of assessment task were used to develop an inventory for student perception of assessment. These dimensions include congruence with planned learning, authenticity, transparency, diversity, and students' consultation of assessment.

In existing research, it is shown that three approaches exist among students when they are inquired about their perception of learning. Surface approach, which recognizes work as an uninvited external obligation and involves completion of learning tasks with minimum personal engagement. It is accompanied by repetitive and unreflective memorization and routine problem solving which restricts conceptual understanding, projecting it as an inevitable outcome. A deep approach, in contrast, starts with an aim of understanding, developing concepts, and conceptually analyzing the task. This generally implies that a deeper level of understanding should thoroughly be carried out, bringing excellence in the learning outcomes. A third approach, namely strategic or achieving approach, based on persistent evidence of effects of assessment on learning, was introduced in which students aimed to achieve the highest possible grades with (1) efficient time management and (2) organized and reliable study methods ( Entwistle, McCune \& Walker, 2001).

Trigwell and Prosser (1991) suggest that instead of discouraging surface approaches, deep approaches are greatly influenced by the methods of assessment and teaching aimed at in-depth learning and conceptual understanding. Therefore, educational policy and methods of teaching play a vital role in fashioning deep learning. Implementation of deep conceptual learning can be made easier with the ideas and advice gained by the students' feedback about the conventional and alternative assessment.

The assessment requirements perceived by students is strongly related to the learning approach adopted by them while tackling an academic task. Students explained that excessive workloads and inappropriate assessment methods develop negative attitudes or surface approach to learning. Therefore, the learning experience is unsatisfactory if the methods of assessment are inappropriate. This dissatisfaction may get masked by the high achievement scores in the traditional terms ignoring the fact that many students may not have understood the task as completely as they seem to have. The inappropriate methods of assessment encourage a surface approach to learning hence, varying the assessment questions will not be enough for thought-provoking and deep approaches (Ramsden, 1997).

Alkharusi (2013) used canonical correlation analyses and correlated students' assessment task perception, motivational orientation, and approaches to learning of 198 tenth grade students, registered in English language courses at Muscat Public school in Oman. Results indicated that the relationships between learning strategies and assessment variables were significant, $F(15,524.91)=$ $18.91, \mathrm{p}<0.001$, and canonical variate account for $67 \%$ of the variance between learning strategy and perception of assessment. An association between transparency along a high degree of authenticity, positive students' self-efficacy and task value dependence on immerse learning strategies were displayed in the overall results.

In research of perceptions of assessment and learning procedures of university students, Ullah, Richardson, and Hafeez (2011) found that students who held firm ideas of the assessment tasks are likely to adopt immerse learning tactics as compared to those who adopt shallow learning tactics because of having a negative attitude towards assessment. These findings show that students differ in their learning strategies based on their ideas of assessment tasks and such perception of assessment tasks must be given reflection for expressions.

A Study by Gulikers, Bastiaens, Kirschner, and Kester (2006) considered the perception of assessment's authenticity and their relationship with student learning in Vocational education and training college, Netherlands. They used quantitative and qualitative methods for data collection from a set of 118 pupils. The instrument used was R-SPQ-2f and statistical analysis, whereas, MANOVA was used to correlate variables. Results showed that the groups of participants bore no resemblance in 
assessment perception and development of generic skills. Overall findings showed that the idea of the assessment task in the focus group developed more generic skills with a deep study approach.

Gijbels, Segers, and Struyf (2008) observed the relationship between assessment task perception and learning strategies in a course of educational psychology for trainee teachers. Their outcomes of the study displayed that deep learning approaches emerge because of good task perception.

Learning and achieving competencies of the $21^{\text {st }}$ century cannot be measured by the simple tests of facts' accumulation. New skills and standards need to be identified for the fulfilment of capabilities (Shute \& Becker (2010). In the educational system in Pakistan post-graduate education, mostly, master-level education is the gateway to enter the workplace. The learned concepts in the classroom are required to be applied in the practical world to meet the competencies and standards of the transforming global change. This study aimed at correlating students' learning approaches with their perception of assessment among different science disciplines at the higher education level.

Objectives of the Study

i) To find learning approaches of students at the higher education level.

ii) To correlate the learning approaches of students at higher education level, with their perception of Assessment.

\section{Research Question}

i) How do learning approaches differ with the perception of assessment tasks at higher education level?

\section{Research Methodology}

\section{Sampling}

The sample of this study was 468 (332 males and 186 females) university students, randomly selected, of master level in the subject of chemistry, biology, and mathematics at 10 general universities (7 public \& 3 private) in KP, Pakistan.

\section{Research Instrument}

An existing instrument redeveloped by Biggs and David (2001) cited in (Gulikers et al., 2006), namely R-SPQ-2F (revised study process questionnaire two factors) and PATI (perception of assessment task inventory) used by Dorman and Knightley (2006) were adapted to evaluate learning approaches and students' assessment task perception respectively.

The R-SPQ-2F questionnaire included 20 items measuring deep motives \& strategies and surface motives \& strategies of the participants. Responses were obtained on a scale of 4 , ranging from 1 (never) to 4 (always) on the Likert scale and the PATI questionnaire included 29 items on six dimensions of perception of assessment ranging from 1 (never) to 4 (always) on a 4-point Likert scale.

\section{Reliability of the Instrument}

The reliability of both R-SPQ-2f and PATI for the responses acquired was evaluated with the help of Cronbach Alpha, which showed a high-reliability coefficient, $\alpha=0.737$ for 20 items of R-SPQ-2f and $\alpha=0.847$ for 29 items of PATI.

\section{Data Collection}

The data was collected by the researcher personally through a questionnaire. It was analyzed through a canonical correlation using SPSS software.

\section{Analysis and Discussion of the Results}

Data were analyzed using SPSS software. It was tabulated, mean values were derived from percentages of responses on a four-point Likert scale, which range from 1 (never) to 4 (always).

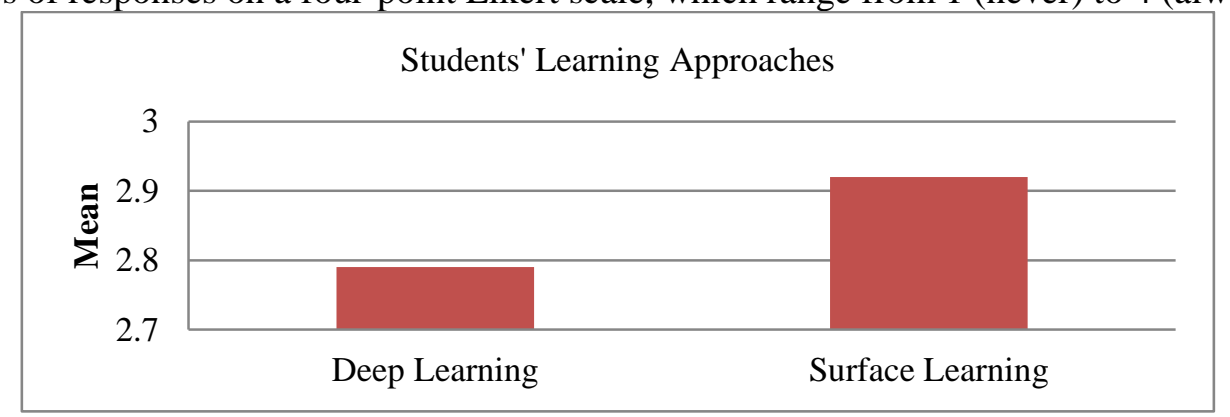

Figure 1, Students' learning approaches in three departments 
Figure 1 shows the mean values of responses against the learning approaches. It is indicated that most students perceive their assessment tasks focusing to get external grades rather than learning. Hence, they developed surface learning strategies, with a mean value of 2.92. The rather depressing findings at the higher education level, have the same results in all three departments under study. At the tertiary level, there is a dire need for creativity and application of learned behavior with the utilization of information making a connection to their daily life. In the study by Ullah et al., (2011) the results showed that negative perception of assessment tasks tends to adopt surface strategies of learning.

Table 1: Descriptive Statistics- Students' learning approaches in three departments

\begin{tabular}{ccccc}
\hline & \multicolumn{2}{c}{ Deep Learning } & \multicolumn{2}{c}{ Surface Learning } \\
\hline Subject Area & Mean & Std. Deviation & Mean & Std. Deviation \\
Chemistry & 2.81 & .365 & 2.97 & .390 \\
Mathematics & 2.71 & .314 & 2.85 & .330 \\
Biology & 2.84 & .386 & 2.95 & .462 \\
\hline
\end{tabular}

Descriptive statistics among the three departments (chemistry, mathematics, and biology) are presented in Table 1. It is indicated that the means of surface learning approaches are high as compared to deep learning approaches. Hence it is assumed that students perceived their assessment tasks as an uninvited external obligation. And this is accompanied by rote learning of facts.

Table 2: Inter Correlations and descriptive statistics for learning approach \& PATI variables

\begin{tabular}{|c|c|c|c|c|c|c|c|c|c|c|c|c|}
\hline & 1 & 2 & 3 & 4 & 5 & 6 & 7 & 8 & 9 & 10 & $M$ & SD \\
\hline 1.CPL & & .067 & $.227^{* *}$ & $.151^{* *}$ & $.216^{* *}$ & $.146^{* *}$ & $.149^{* *}$ & $.260^{* *}$ & $.247^{* *}$ & .070 & 2.50 & .547 \\
\hline 2.AA & & & $.230^{* * *}$ & $.475^{* * *}$ & $.416^{* * *}$ & $.362^{* * *}$ & $.254^{* *}$ & .040 & $.430^{* * *}$ & $.755^{* *}$ & 3.06 & .541 \\
\hline 3.SCA & & & & $.737^{* *}$ & $.444^{* *}$ & $.292^{* *}$ & $.439^{* * *}$ & $.369^{* * *}$ & $.309^{* * *}$ & $.246^{* *}$ & 2.67 & .557 \\
\hline 4.T & & & & & $.390^{* *}$ & $.351^{* *}$ & $.297^{* *}$ & .014 & $.191^{* * *}$ & $.384^{* * *}$ & 2.98 & .583 \\
\hline 5.D & & & & & & $.222^{* *}$ & $.119^{*}$ & $.600^{* *}$ & $.426^{* * *}$ & $.317^{* * *}$ & 2.51 & .533 \\
\hline 6. FB & & & & & & & $.302^{* * *}$ & $.156^{* *}$ & $.284^{* * *}$ & $.481^{* *}$ & 2.93 & .463 \\
\hline 7. DM & & & & & & & & $.198^{* *}$ & $.291^{* *}$ & $.291^{* * *}$ & 3.04 & .476 \\
\hline 8. DS & & & & & & & & & $.694^{* * *}$ & $.111^{*}$ & 2.54 & .459 \\
\hline 9. SM & & & & & & & & & & $.493^{* * *}$ & 2.80 & .438 \\
\hline 10. SS & & & & & & & & & & & 3.05 & .493 \\
\hline
\end{tabular}

**. Correlation is significant at the 0.01 level (2-tailed).

*. Correlation is significant at the 0.05 level (2-tailed).

Correlations among variables (Table 2) displayed a variation between 0.19 and 0.69 . The assessment perception of students ranged from 0.06 to 0.73 . Whereas, the correlation among the learning approaches and the perception of assessment tasks ranged from 0.01 to 0.75 . Authenticity and surface strategy, when taken as a pair, shows a good correlation $(r=0.75)$, which asserts that students rely on cramming. Whereas, diversity has a good correlation with deep strategy $(r=0.60)$ relating to students' capabilities and applying their learning depending on the assessment tasks.

For comparison between the above-mentioned assessment variables i.e. learning and perception, a canonical correlation analysis was conducted. The analysis evaluates the relationship of variance shared by the two variables (learning approaches and student perception) using the four learning approach variables (deep motive, deep strategy, surface motive \& surface strategy) as predictors of the six students' perception variables (congruence with planned learning, authenticity, students' consultancy, transparency, diversity, and feedback of assessment).

Four functions were yielded in the analysis with squared canonical correlations $\left(\mathrm{R}_{\mathrm{c}}{ }^{2}\right)$ of .663, $.624, .168$, and .038 for each successive root. Statistical significance exists for all functions of model using Wilks's Lambda $(\lambda)=.101$ criterion, $F(24,1455.95)=56.3, p<.000$. The full model explained $90 \%$ of the variance shared by the sets of variables, which was indicated by the $r^{2}$ type effect size (.90).

Table 3: Eigenvalues and Canonical Correlations for Each Covariate Separately

\begin{tabular}{ccccc}
\hline Root No & Eigenvalue & \% & Canon Cor & Sq. Cor $\left(\mathbf{R c}^{2}\right)$ \\
\hline 1 & 1.96 & 50.84 & .814 & .663 \\
2 & 1.65 & 42.87 & .789 & .624
\end{tabular}




\begin{tabular}{lllll}
\hline 3 & .20 & 5.25 & .411 & .168 \\
4 & .04 & 1.03 & .196 & .038 \\
\hline Given the $R_{c}^{2}$ effects for each canonical variate as shown in
\end{tabular}

Given the $R_{c}{ }^{2}$ effects for each canonical variate as shown in Table 3, in the current context the noteworthy roots were only the first two $(66 \%$ and $62 \%$ of the shared variance, respectively). After excluding these two roots from the variable sets, the remaining two only explained $16 \%$ and $3.8 \%$ variance, respectively.

Table 4: Canonical Solution for Students' Perception Predicting Learning Approaches for Roots 1 and 2

\begin{tabular}{llllllll}
\hline \multicolumn{1}{c}{ Variable } & \multicolumn{3}{c}{ Root 1 } & \multicolumn{5}{c}{ Root 2 } \\
\cline { 2 - 8 } & Coef & $R s$ & $r s^{2}(\%)$ & Coef & $r s$ & $r s^{2}(\%)$ & $h^{2}(\%)$ \\
\hline DM & -.130 & -.307 & 9.4 & -.139 & -.390 & 15.2 & 24.6 \\
DS & .755 & .340 & 11.5 & -1.04 & -.896 & 80.2 & 91.7 \\
SM & -.454 & -.297 & 8.8 & .330 & -.673 & 45.2 & 54.0 \\
SS & -.669 & -.847 & 71.7 & -.485 & -.478 & 22.8 & 94.5 \\
$\boldsymbol{R}_{c}{ }^{2}$ & & & 66.3 & & & 62.4 & \\
CPL & .014 & .02 & .04 & -.068 & -.308 & 9.4 & 9.44 \\
AA & -.922 & -.864 & 74.6 & -.204 & -.381 & 14.5 & 89.1 \\
SCA & .109 & -.102 & 1.04 & -.712 & -.586 & 34.3 & 35.3 \\
TA & -.231 & -.457 & 20.8 & .751 & -.226 & 5.1 & 25.9 \\
DA & .504 & .039 & .01 & -.648 & -.830 & 68.8 & 68.8 \\
FB & -.190 & -.458 & 20.9 & -.264 & -.436 & 19.0 & 39.9 \\
\hline
\end{tabular}

Note. Structure coefficients $(r \mathrm{~s})$ greater than $|.45|$ are considered in discussion. Communality coefficients $\left(h^{2}\right)$ greater than $45 \%$ are considered. Coef $=$ standardized canonical function coefficient; $r s=$ structure coefficient; $r s^{2}=$ squared structure coefficient; $h^{2}=$ communality coefficient

Structure coefficients and standardized canonical coefficients for roots 1 and 2 are presented in Table 4. For each variable of the two roots, the squared structure coefficients, and the communalities $\left(h^{2}\right)$ is also given. Root 1 coefficients show surface strategy with deep motives were primary criterion variables. Whereas, secondary criterion variables were surface motives with deep strategy. Furthermore, the same signs in all the variable' structure coefficients indicated a positive relationship with each other except deep strategy which was related inversely to other sets of variables. Predictor variable in root 1 shows the authenticity of assessment, transparency of assessment, and feedback perception as primary contributors. Whereas, consultation of assessment, diversity of student capabilities, and congruence with planned learning were secondary contributors. Because the structure coefficient for diversity and congruence with planned learning were positive, they were negatively related to all the learning approaches except the deep strategy. Authenticity, transparency, and feedback were positively related to the learning approaches, again excluding the deep strategy. Hence the perception of authenticity of assessment task has a reliance on surface strategies. This means that assessment tasks related to real-life situations demanded less effort by the students. In other words, students have surface strategies regarding authentic assessment tasks.

Criterion relevance variables shown in root 2 were deep strategy, surface motives, and surface strategy. There was a positive relation between deep strategy and surface strategy, while surface motive was inversely related to this root. As for perception, the dominant predictors were student consultancy and diversity, along with feedback. All of these were also positively related. The structure coefficients for predictor and synthetic variables indicate a positive relation between deep strategy, surface strategy, and student consultancy, diversity, and feedback. Surface motives had the opposite pattern. Hence, it is assumed that assessment practice in the classroom motivates students for activities that lead to surface learning. It is also assumed that emergence of surface learning approaches was due to low cognitive tasks in the classroom. Presented in Table 1, it is indicated that students of mathematics show less deep learning as compare to students of chemistry and biology departments. Hence, problem-solving activities with prompt feedback can initiate critical thinking.

\section{Conclusions}

These findings were in favor of apparent relationships between students' perception and learning and we assumed canonical correlation root 1 as the perception of authenticity of assessment with surface strategies and root 2 as students' consultancy and diversity of their capabilities with deep and surface 
strategies. This asserts that depending on their understanding of assessment tasks, students may differ in their strategies and learning approaches.

Through the findings of this study, it is concluded that students have a reliance on the surface learning approaches, which is due to the negative perception of the assessment task. It was concluded that the use of specific assessment methods in the classroom leads to low cognitive activities. It was further concluded that deep learning approaches are fortified by the varied assessment methods and designed instructions, rather than trying to discourage surface learning approaches.

\section{Suggestions}

Instructors can help students in developing deep learning strategies by using varied assessment methods mostly alternative forms of assessment, like self \& peer assessment, etc. along with traditional assessment methods. Additionally, consulting students regarding the purpose of assessment and involving them in the assessment process might make the classroom environment suitable for motivating students to acquire conceptual learning. Providing prompt feedback additionally motivates students towards deep learning, which in turn develops high self-efficacy in them and thus leads them to attain their goals of high competencies for the workplace, successfully.

\section{References}

Alkharusi, H. (2013). Canonical Correlational Models of Students' Perceptions of Assessment Tasks, Motivational Orientations, and Learning Strategies. In International Journal of Instruction (Vol. 6).

Black, P., \& Wiliam, D. (1998). Assessment and Classroom Learning. Assessment in Education: Principles, Policy \& Practice, 5(1), 7-74. https://doi.org/10.1080/0969595980050102

Bransford, J. D., Brown, A. L., \& Cocking, R. R. Council, N. R. (2000). How People Learn: Brain, Mind, Experience, and School: Expanded Edition. https://doi.org/10.17226/9853

Dorman, J. P., \& Knightley, W. M. (2006). Development and validation of an instrument to assess secondary school students' perceptions of assessment tasks. Educational Studies, 32(1), 4758. https://doi.org/10.1080/03055690500415951

Entwistle, N., McCune, V., \& Walker, P. (2001). Conceptions, styles, and approaches within higher education: Analytical abstractions and everyday experience. Lawrence Erlbaum Associates.

Gijbels, D., R.Segers, M., \& Struyf, E. (2008). Constructivist learning environments and the (im)possibility to change Students' perceptions of assessment demands and approaches to learning. In Instructional Science (Vol. 36). https://doi.org/10.1007/s11251-008-9064-7

Gulikers, J. T. M., Bastiaens, T. J., Kirschner, P. A., \& Kester, L. (2006). Relations between student perceptions of assessment authenticity, study approaches, and learning outcome. Studies in Educational Evaluation, 32(4), 381-400. https://doi.org/https://doi.org/10.1016/j.stueduc. 2006.10.003

Klimoski, V. (2006). Assessment Clear and Simple: A Practical Guide for Institutions, Departments, and General Education - Barbara E. Walvoord. In Teaching Theology \& Religion (Vol. 9). https://doi.org/10.1111/j.1467-9647.2006.00283_1.x

Palomba, C. A., \& Banta, T. W. (1999). Assessment Essentials: Planning, Implementing, and Improving Assessment in Higher Education. Higher and Adult Education Series. ERIC.

Ramsden, P. (1997). The context of learning in academic departments. The Experience of Learning, 2, 198-216.

Shute, V. J., \& Becker, B. J. (2010). Innovative assessment for the 21 st century. Springer.

Stiggins, R., \& Chappuis, J. (2005). Using Student-Involved Classroom Assessment to Close Achievement Gaps. Theory Into Practice, 44(1), 11-18. https://doi.org/10.1207/s15430421tip 4401_3

Trigwell, K., \& Prosser, M. (1991). Improving the Quality of Student Learning: The Influence of Learning Context and Student Approaches to Learning on Learning Outcomes. Higher Education, 22(3), 251-266. Retrieved from http://www.jstor.org/stable/3447175

Ullah, R., Richardson, J. T. E., \& Hafeez, M. (2011). Approaches to studying and perceptions of the academic environment among university students in Pakistan. Compare: A Journal of Comparative and International Education, 41(1), 113-127. https://doi.org/10.1080/0305792 1003647065 